\section{The art of aortic valve repair}

\author{
Lars G. Svensson, MD, PhD
}

In cardiac surgery, as with many endeavors, there is a point to which science can take you, and then art-namely observation, hands-on skill, craft, imagination, and mental imputation-must take over. And so it is with aortic valve repairs. Certainly, there are some important physics principles to note: (1) the greater the contact area of leaflet to leaflet apposition, the less leakage; (2) according to Poiseuille equation, small changes in the diameter of an orifice lead to large gradient increases by radius to the fourth power; (3) the longer the leaflets, the greater likelihood of turbulence and gradients (ie, increased shear over a longer distance at the boundary layer disrupting laminar flow); (4) tension and the risk of leaflet tear or perforation are increased with less apposition of leaflets to relieve linear edge stress; (5) greater leaflet height increases the contact area of apposition without sacrificing orifice area; and (6) there is increased stasis and likelihood of clot formation (Virchow's triad) with sinuses that are too deep, particularly with added pericardium.

Based on these principles, usually with aortic valve repair, regurgitation is less with increasing pressure load on the leaflets when coming off pump compared with mitral valve repair, in which case worsening of regurgitation occurs.

There is no shortcut to successful aortic valve repairs. It is a matter of observation, experience, and time "spent" on the learning curve to understand what a normal tricuspid leaflet valve should look like, and for bicuspid valves, what works. After performing well over 1000 aortic valve repairs, reimplantations, and remodelings, I am convinced that achieving a competent and nonstenotic aortic valve is more art than science. ${ }^{1-6}$ Measurements are of little value when, for

\footnotetext{
From the Department of Thoracic and Cardiovascular Surgery and The Aorta Center, Heart, Vascular, and Thoracic Institute, Cleveland Clinic, Cleveland, Ohio. This work was partially funded by Friends of Cleveland Clinic Foundation and the Delos M. Cosgrove, MD, Chair for Heart Disease Research. Dr Svensson is an unpaid member of the executive committee for PARTNER trials I and II, chairman of the PARTNER Publication Committee, and an unpaid member of the executive committee of the COMMENCE (ProspeCtive, nOn-randoMized, MulticENter Clinical Evaluation of Edwards Pericardial Bioprostheses With a New Tissue Treatment Platform) trial, sponsored by Edwards Lifesciences, and co-national PI for the PROACT Xa Trial.

Received for publication Jan 20, 2021; accepted for publication Jan 20, 2021; available ahead of print Jan 28, 2021.

Address for reprints: Lars G. Svensson, MD, PhD, Heart, Vascular, and Thoracic Institute, Cleveland Clinic, 9500 Euclid Ave/J1-227, Cleveland, OH 44195 (E-mail: svenssl@ccf.org).

JTCVS Techniques 2021;7:121-5

2666-2507

Copyright (C) 2021 The Authors. Published by Elsevier Inc. on behalf of The American Association for Thoracic Surgery. This is an open access article under the CC BY-NCND license (http://creativecommons.org/licenses/by-nc-nd/4.0/).

https://doi.org/10.1016/j.xjtc.2021.01.030
}

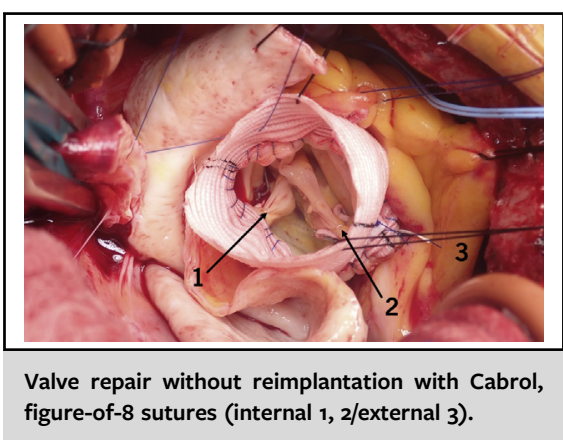

CENTRAL MESSAGE

Surgeons must understand principles of aortic root repair; consider the aortic valve, root, and components as a unit; and observe many repairs to learn the art of successful repair.

See Commentaries on pages 126 and 128.

example, the tying suture sequence during reimplantation changes the geometry of the leaflets.

Critical to a successful repair is considering the aortic valve, the root, and its components as a unit to obtain early and late competence. Thus, all components of the CLASS schema (commissures, leaflets, anulus, sinuses, and sinutubular junction) need to function in concert for a successful repair (Table 1). This helps determine the appropriate technique to use (Table 2).

There are some basic leaflet repair techniques that can be used in $90 \%$ of cases with great success (Figures 1 and 2, A and $B),{ }^{1}$ some of which a historic innovations, including Cabrol sutures, commissure apposition stitches, Trussler stitches, and running polytetrafluoroethylene (PTFE) sutures on the leading cusp edge, a technique that may reduce late leaflet prolapse. ${ }^{7}$ Cabrol described placing stitches at the base of the commissure to increase apposition of leaflets. ${ }^{8}$ This typically works well for bicuspid valves, but

TABLE 1. CLASS schema

\begin{tabular}{ll}
\hline C & Commissures \\
L & Leaflets \\
A & Anulus \\
S & Sinuses \\
S & Sinutubular junction \\
\hline
\end{tabular}


TABLE 2. Assessment of the valve unit

\begin{tabular}{lll}
\hline & \multicolumn{1}{c}{ Assessment } & \multicolumn{1}{c}{ Possible solutions } \\
\hline Commissures & Height, orientation, apposition, tears, fusion & Figure-of- $8,{ }^{*}$ Cabrol stitch, $\dagger$ tissue excision $\ddagger$ \\
Leaflets & $\begin{array}{c}\text { Tears, perforations, prolapse, incomplete fusion, thickness, edge, } \\
\text { noduli of Aranti, cupping depth }\end{array}$ & Repairs, Trussler stitch, running edge, $\S$ suture plication, shaving \\
Anulus & $\begin{array}{c}\text { Size (eg, CT area, diameter, radius, concentricity); subanular } \\
\text { stenosis/LVOT obstruction }\end{array}$ & $\begin{array}{c}\text { Anular reduction with a Hegar dilator, bracing, myectomy, rarely } \\
\text { anular enlargement for repair }\end{array}$ \\
Sinuses & Both native and artificial with reimplantation or remodeling & $\begin{array}{c}\text { Division of raphe, } \| \text { rarely patch, create new sinuses with } \\
\text { reimplantation }\end{array}$ \\
$\begin{array}{c}\text { Sinutubular } \\
\text { junction }\end{array}$ & Splayed or narrow? Will figure-of-8 stitch be accommodated? & $\begin{array}{c}\text { Narrow with reimplantation, splay with bicuspid remodeling, tailor } \\
\text { or smaller for tricuspid valve repairs }\end{array}$ \\
\hline
\end{tabular}

$C T$, Computed tomography; LVOT, left ventricular outflow tract. *Used most commonly for repairs. †For a large anulus, either bicuspid- or trileaflet-associated valve, and no reimplantation. †़For an ideal unicuspid valve that can be turned into a bicuspid valve. §This can be used to try to reduce late prolapse in the thicker bicuspid valve leaflets, in combination with tying the suture around a Hegar dilator. "This should be a deep cut to free up the body of the conjoint leaflet.

not for trileaflet valves; however, the surgeon must be careful not to place the stitches too low and thereby create stenosis or turbulence. Furthermore, in the long term, these sutures can result in clot deposition, fibrous formation, stenosis, and calcification. During remodeling, the beveled graft can be sewn to these sutures to brace the anulus instead of placing a circumferential brace, such as with PTFE sutures, felt, or one of the newer materials/devices. I find that use of the PTFE suture as a left ventricular outflow tract (LVOT) circumferential suture increases the risk of pacemakers; the only late failure that I have experienced with this suture resulted in a LVOT membrane and stenosis.

The Trussler stitch is used to shorten the edge of a leaflet at a commissure. A suture is woven through the leaflet edge near the commissure and then tied to shorten the length. It is an alternative to mid-leaflet plication, but I rarely use it, because I find that the tension on the sutures sometimes results in leading-edge tears at the commissures. Plication of the leaflet has better durability if leaflets are prolapsing or for an incomplete fusion. In addition, resection and suture leaflets carries a greater risk of leakage through the suture line and of late failure. If after placing figure-of- 8 sutures, trileaflet valve prolapse remains, I use a mid-leaflet plication stitch. For prolapse, a 1-mm plication with a horizontal mattress suture is often all that is needed (see below). As with mitral valve repairs, the less done the better in many cases. For incomplete fusions, I first do a running 2-layer polyester stitch for strength to get the approximate symmetrical orientation for a bicuspid valve and then finish the repair with a horizontal mattress suture to get the best possible symmetry without any prolapse when testing with 2 forceps (Figure 2,B). This is further improved by figure-of- 8 adjusting sutures. Running PTFE sutures along the leaflet edge should be used with care but may improve long-term durability of particularly long bicuspid valve leaflets. Usually, the leaflet edge in bicuspid valves is a little

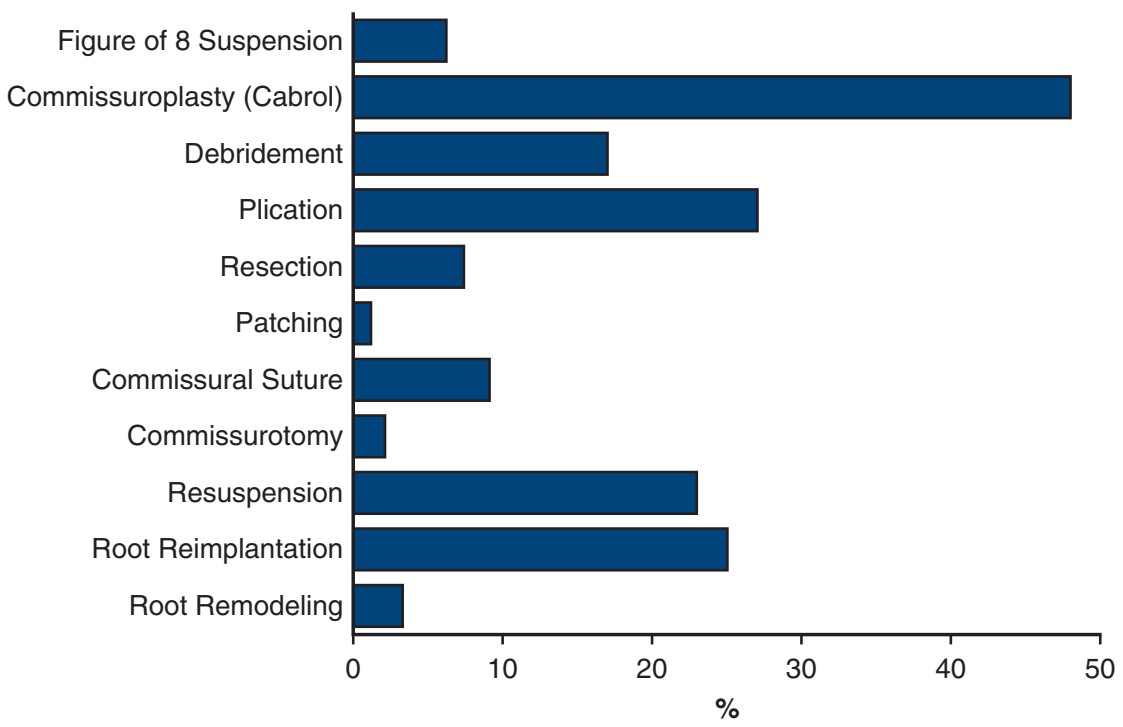

FIGURE 1. Use of different types of repair methods on aortic valves. ${ }^{1}$ 

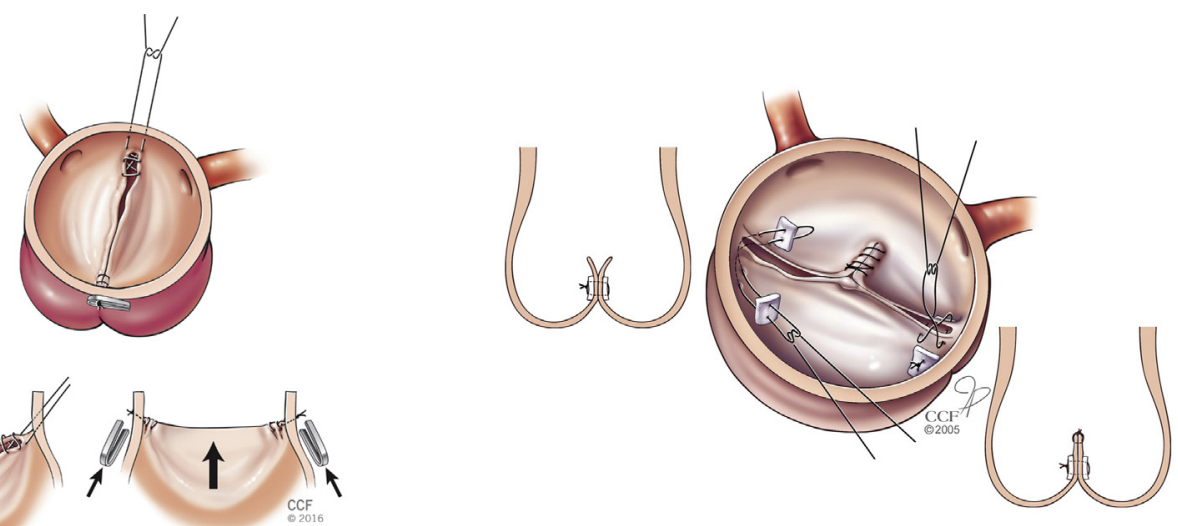

A
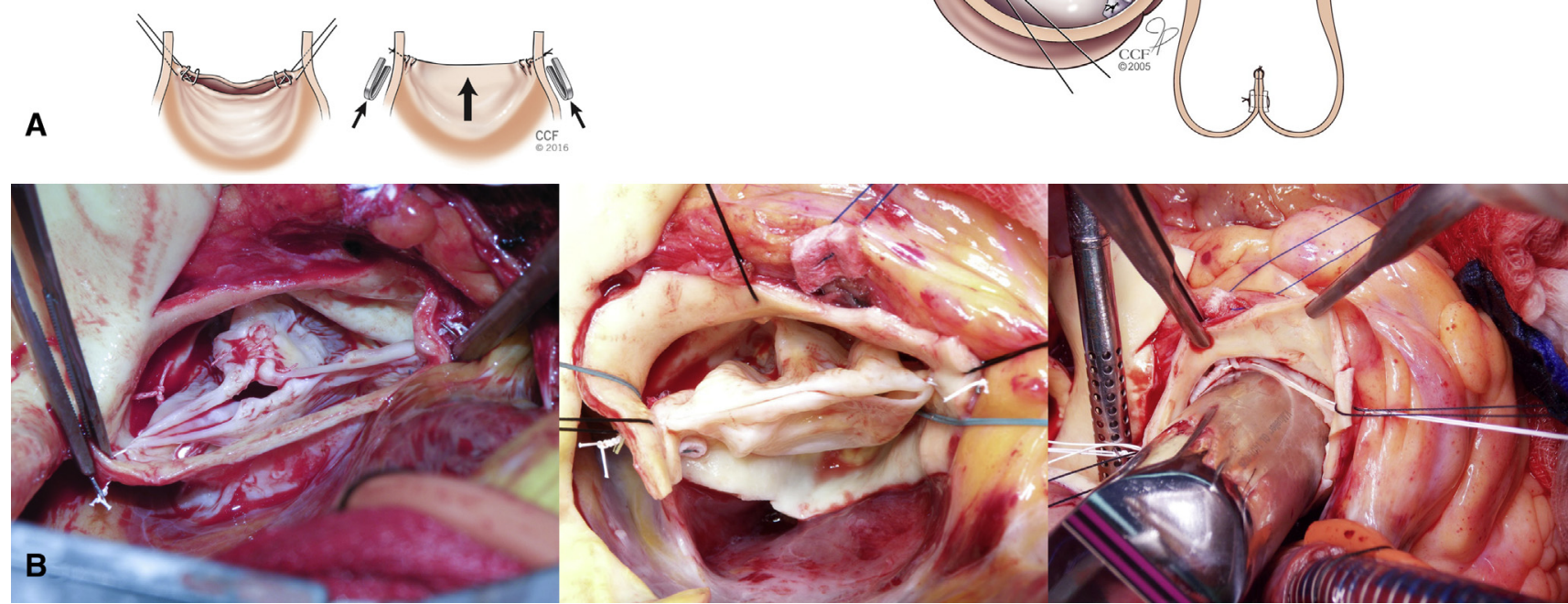

FIGURE 2. A, Newer techniques for aortic valve repair, the first of which involves placing figure-of- 8 suspension sutures at the leading edge of the cusps. Cabrol commissuroplasty showing 2 commissural stitches (pledgeted and commissural approximation) and central plication (Reproduced with permission from Zeeshan and colleagues. ${ }^{1}$ ). B, Intraoperative photographs of bicuspid repairs with Cabrol, plication, leaflet edge, and figure-of-8 sutures. Note the use of a Hegar dilator to ensure that no stenosis is created.

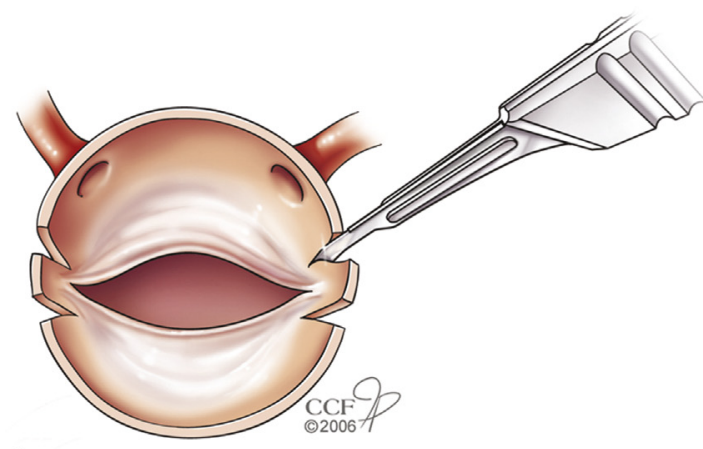

A

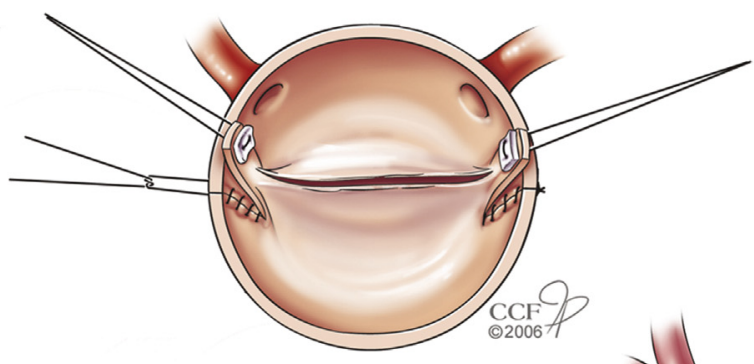

B

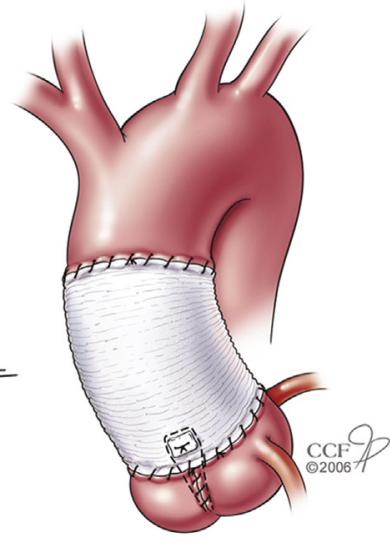

FIGURE 3. Suturing commissures at a higher level. A, Mobilizing commissure for a large root. B, Closing gaps in aortic root incisions. C, Reattachment of commissures resuspended in a tube graft at a higher level. (Reproduced with permission from Svensson and colleagues. ${ }^{9}$ ) 


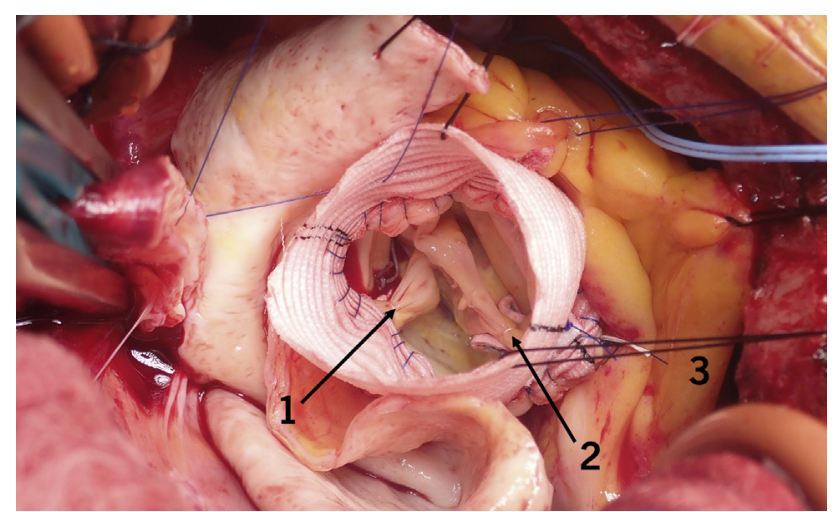

FIGURE 4. Trileaflet valve repair with a separate ascending tube graft. Note the Cabrol sutures at the base of commissures and figure-of- 8 suspension sutures. The patient went from $3+$ regurgitation to none.

thickened and will hold sutures; however, if the leaflet tissue is thin and reliance is placed on this suture to "suspend" the leaflet edge, it may tear out. I tie the suture outside the aorta, do both leaflets, and use it in combination with figure-of- 8 sutures tied down around a Hegar dilator of at least $21 \mathrm{~mm}$ (Figure 2, B).

Having been of the conviction that placing commissures at a higher level would correct and compensate for prolapse, I initially went through a period where I cut the commissures free, closed the gap outside of the freed commissures, and then reimplanted the commissures in a tube graft at a higher level (Figure 3). ${ }^{9}$ In approximately 10 patients, this worked very well in obtaining a competent valve without stenosis; however, as this was often for thinned dilated roots, with tension on suture lines, bleeding from the suture lines had to be carefully controlled. Nevertheless, I am not aware of any patient requiring reoperation.
For patients who do not need their valves lifted as much, the alternative is to place a PTFE stitch over and over at the leading edge of the leaflets near the commissures. This better opposes them and provides more strength in terms of leaflet tearing compared with the Trussler stitch. I then suspend the sutures 3 to $4 \mathrm{~mm}$ higher and tie them on the outside, about 3 to $4 \mathrm{~mm}$ apart (Figure 2). ${ }^{1}$ The PTFE may provide some elasticity in absorbing the pressure load of the returning diastolic pressure wave. I use this routinely for bicuspid valve repairs (Figure 2$)^{1}$ and trileaflet repairs (Figure 4, arrows), isolated repairs with an ascending tube graft, remodeling, and reimplantation of trileaflet or bicuspid valves if there is asymmetry with prolapse. Apart from raising the level of the commissures, this technique can be used to move a commissure in an opposite direction to a prolapsing leaflet and increase tension of the prolapsing leading edge. Of note, these sutures rarely need more than 1 to $3 \mathrm{~mm}$ of adjustment of the leaflet edge. Initially, in my early experience with the modification of the David reimplantation operation (Figure 5), ${ }^{7}$ using pledgets in the LVOT tract and a Hegar dilator to reduce the anulus to a normalized valve for body surface area diameter, roughly 1 in 4 patients needed additional leaflet repairs, mostly with figure-of- 8 sutures. ${ }^{2-4}$ However, as our experience has continued, having performed 1113 reimplantations as of December 2020, I rarely need to place figure-of- 8 sutures or do plications. Leaflet prolapse, particularly of the right cusp, usually can be adjusted by moving the commissure away from the prolapsing leaflet to improve suspension of the leaflet.

In 2014, we reported on 728 bicuspid aortic valve repairs with $91 \%$ freedom from reoperation at 10 years, ${ }^{9}$ but recent repairs using more modern techniques appeared to be holding up better. Similarly, in the large series of $>1000$ recent
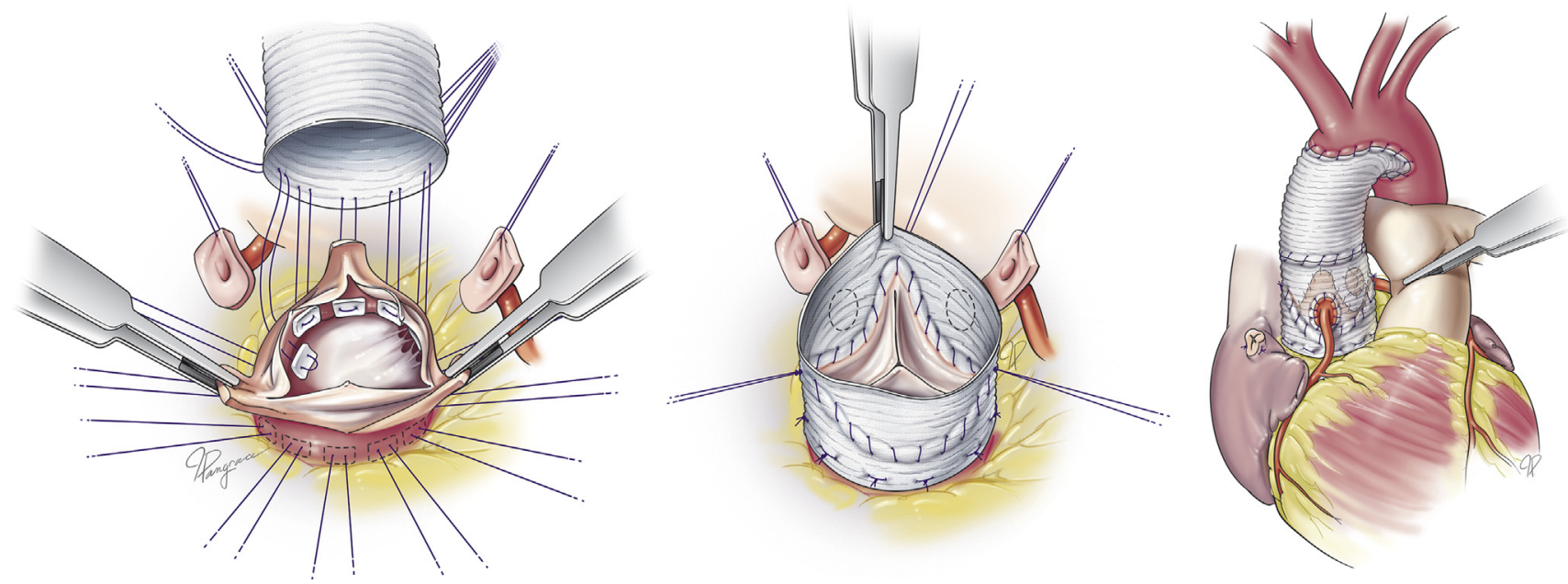

FIGURE 5. Steps in modified reimplantation with pledgeted sutures, a Hegar dilator for normal body surface area anular size (not shown), and completion of reimplantation/repair. (Reproduced with permission from Mokashi and colleagues. ${ }^{7}$ ) 


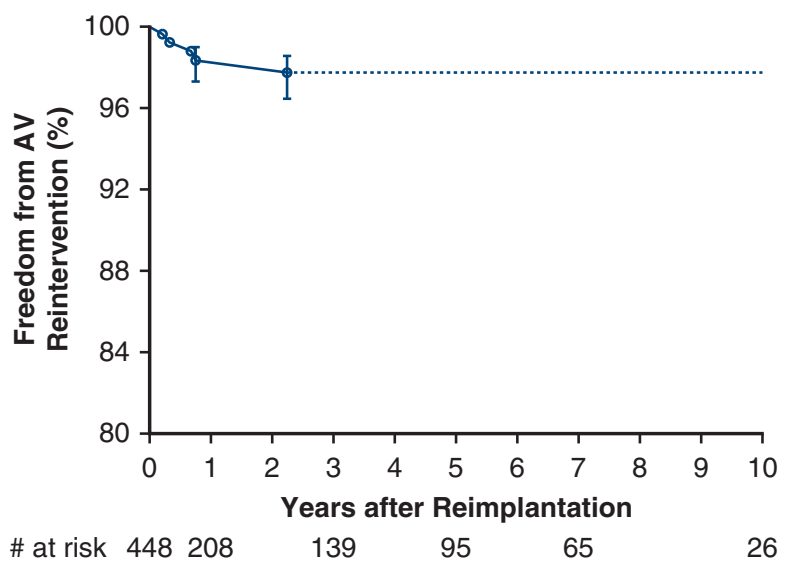

FIGURE 6. Freedom from reoperation after reimplantation.

aortic valve repairs, ${ }^{1}$ bracing the root and using figure-of- 8 sutures were associated with long-term durability. Note the many repair techniques used in attempts to achieve a durable repair (Figure 1). Nevertheless, a word of caution is needed. With appropriate selection of patients based on age and clinical findings, one should be "conservative" in doing repairs. Namely, the patient should be a good candidate for successful repair, with no calcification of the leaflets, no major perforations, and not more than 2 prolapsed leaflets. Furthermore, freedom from reoperation at 10 years after reimplantation with the techniques described has been $97 \%$ (Figure 6). The risk of death for elective reimplantation surgery is $0.17 \%$. As of the end of 2020 , we had completed a total of 4680 aortic valve repairs, of which 1430 were for bicuspid, unicuspid, or quadricuspid valve repairs performed at Cleveland Clinic.

Although aortic valve repair can be tricky, by adhering to the principles and techniques described herein and observing the operation being done by seasoned experts, with experience, the art of aortic valve repair can be learned.

\section{Conflict of Interest Statement}

The author reported no conflicts of interest.

The Journal policy requires editors and reviewers to disclose conflicts of interest and to decline handling or reviewing manuscripts for which they may have a conflict of interest. The editors and reviewers of this article have no conflicts of interest.

\section{References}

1. Zeeshan A, Idrees JJ, Johnston DR, Rajeswaran J, Roselli EE, Soltesz EG, et al Durability of aortic valve cusp repair with and without annular support. Ann Thorac Surg. 2018;105:739-48.

2. Svensson LG, Deglurkar I, Ung J, Pettersson G, Gillinov AM, D’Agostino RS et al. Aortic valve repair and root preservation by remodeling, reimplantation, and tailoring: technical aspects and early outcome. J Card Surg. 2007;22:473-9.

3. Svensson LG, Blackstone EH, Alsalihi M, Batizy LH, Roselli EE, McCullough R, et al. Midterm results of David reimplantation in patients with connective tissue disorder. Ann Thorac Surg. 2013;95:555-62.

4. Svensson LG, Batizy LH, Blackstone EH, Gillinov AM, Moon MC, D'Agostino RS, et al. Results of matching valve and root repair to aortic valve and root pathology. J Thorac Cardiovasc Surg. 2011;142:1491-8.e7.

5. Svensson LG, Cooper M, Batizy LH, Nowicki ER. Simplified David reimplantation with reduction of anular size and creation of artificial sinuses. Ann Thorac Surg. 2010;89:1443-7.

6. Svensson LG. Sizing for modified David's reimplantation procedure. Ann Thorac Surg. 2003;76:1751-3.

7. Mokashi SA, Rosinski BF, Desai MY, Griffin BP, Hammer DF, Kalahasti V, et al. Aortic root replacement with bicuspid valve reimplantation: are outcomes and valve durability comparable to those of tricuspid valve reimplantation? J Thorac Cardiovasc Surg. May 11, 2020 [Epub ahead of print].

8. Cabrol C, Cabrol A, Guiraudon G, Bertrand M. [Treatment of aortic insufficiency by means of aortic annuloplasty]. Arch Mal Coeur Vaiss. 1966;59:1305-12 [in French].

9. Svensson LG, Al Kindi AH, Vivacqua A, Pettersson GB, Gillinov AM, Mihaljevic T, et al. Long-term durability of bicuspid aortic valve repair. Ann Thorac Surg. 2014;97:1539-48.

Key Words: aorta, cardiac surgery, Cabrol stitch, CLASS, figure-of-eight suture, leaflet repair, reimplantation, Trussler stitch, valve leaflet 